\title{
CORONARY ARTERY FISTULA DRAINING INTO THE LEFT VENTRICLE
}

\author{
JIHYUN SOHN, MD, JONG-MIN SONG, MD, PHD, JEONG YOON JANG, MD, BYUNG JOO SUN, MD, \\ DAE-HEE KIM, MD, PHD, DUK-HYUN KANG, MD, PHD, AND JAE-KWAN SONG, MD, PHD \\ DIVISION OF CARDIOLOGY, ASAN MEDICAL CENTER, UNIVERSITY OF ULSAN COLLEGE OF MEDICINE, SEOUL, KOREA
}

We present a case of 48-year-old male who presented with coronary artery fistula draining into left ventricle. Transthoracic echocardiography showed abnormal blood flow draining into left ventricle, with enlarged coronary arteries and multiple vascular structures around ventricular myocardium. Coronary computed tomography revealed dilatation of entire left coronary artery which was wrapping around left ventricle, and draining into the posterior side of left ventricle. He did not undergo any invasive treatment, because he was not symptomatic.

KEY WORDS: Coronary artery fistula $\cdot$ Echocardiography $\cdot$ Computed tomography.

\section{INTRODUCTION}

A coronary artery fistula $(\mathrm{CAF})$ is an abnormal communication between one of the coronary arteries and a cardiac chamber or vessels, including the coronary sinus, pulmonary artery, or superior vena cava. ${ }^{1-3)} \mathrm{CAF}$ is involved in $0.002 \%$ of general population and accounts for $0.4 \%$ of all cardiac malformation. ${ }^{4)}$ CAF mostly drains into the venous structures of circulation, such as the right-sided chambers, pulmonary artery, coronary sinus and superior vena cava, but drainage into the leftsided chambers is less frequent. ${ }^{5)}$ We present a case of CAF which is originated from left coronary artery and drained into left ventricle.

\section{CASE}

A 48-year-old male presented with abdominal pain that had lasted for 2 months. He had no cardiovascular risk factor, and no cardiovascular symptom such as chest pain or dyspnea. He was diagnosed as gallbladder stone and admitted to our hospital for laparoscopic cholecystectomy. Preoperative electrocardiography was within normal limit, and chest X-ray showed no pathologic abnormality. He was consulted to cardiovascular department because surgeon heard a continuous cardiac murmur and ordered echocardiography for a preoperative evaluation. The echocardiography showed normal ejection fraction (64\%). The mitral inflow E/A ratio was 1.63 , and $\mathrm{E} / \mathrm{E}$ ' ratio was 12.0. The valvular morphology and function was normal. However, there was abnormal color flow within left ventricle predominantly during diastole (Fig. 1, Supplementary movie 1-4). It was originated from basal posterior wall and drained into the left ventricular cavity. The maximal velocity of blood flow draining into left ventricle was approximately $3.0 \mathrm{~m} / \mathrm{s}$. In short-axis great arterial view, left coronary artery appeared dilated. Multiple tortuous dilated vascular structures with internal blood flows disclosed by color Doppler image were also found around left ventricular myocardium. Especially, dilated large echo-free vascular structure was detected in the apical area. The connection between those dilated vascular structures and left coronary artery was suspected, but clear visualization of the connection was limited in 2-dimensional echocardiography. Coronary artery computed tomography (CT) scan was performed to confirm the pathologic anatomy of these abnormal findings. Coronary CT revealed markedly dilated (up to $16 \mathrm{~mm}$ ) and serpentine whole left coronary arteries (Fig. 2). The left anterior descending artery was communicating with left circumflex artery at the apical posterior epicardium, and was directly connected to the basal posterior side of left ventricular cavity (Fig. 3). He was finally diagnosed as having CAF.

Since the patient had no cardiovascular symptom, he underwent laparoscopic cholecystectomy without specific treatment

\footnotetext{
- Received: July 19, 2013 •Revised: January 10, 2014 •Accepted: February 18, 2014

- Address for Correspondence: Jong-Min Song, Division of Cardiology, Asan Medical Center, University of Ulsan College of Medicine, 88 Olympic-ro 43-gil,

Songpa-gu, Seoul 138-736, Korea Tel: +82-2-3010-3168, Fax: +82-2-486-5918, E-mail: jmsong@amc.seoul.kr

- This is an Open Access article distributed under the terms of the Creative Commons Attribution Non-Commercial License (http://creativecommons.org/licenses/by-nc/3.0)

which permits unrestricted non-commercial use, distribution, and reproduction in any medium, provided the original work is properly cited.
} 

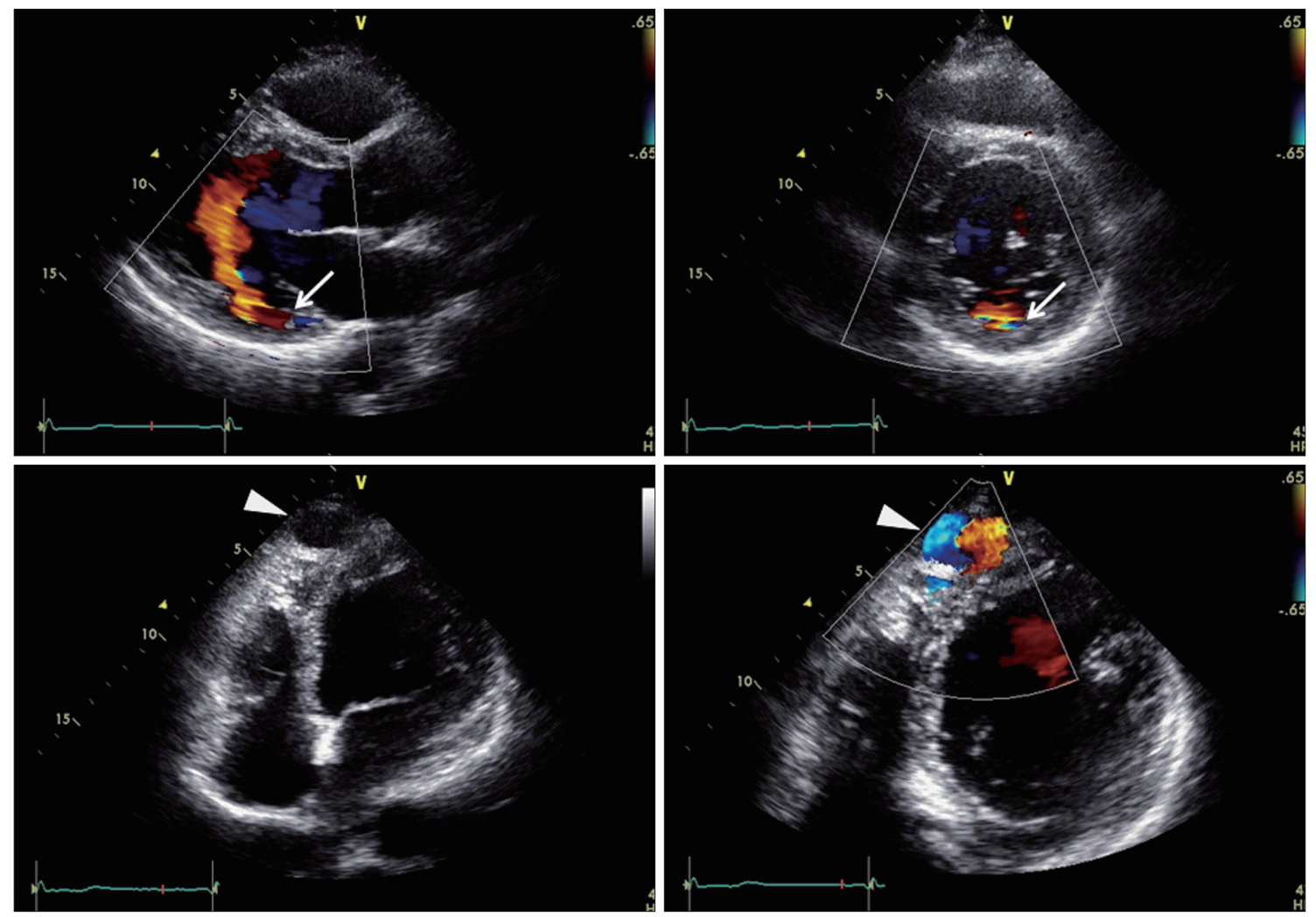

Fig. 1. Abnormal flow draining into the basal posterior portion of left ventricle (arrows) and dilated large echo-free vascular structure (arrowheads), revealed by transthoracic echocardiography and color Doppler images.
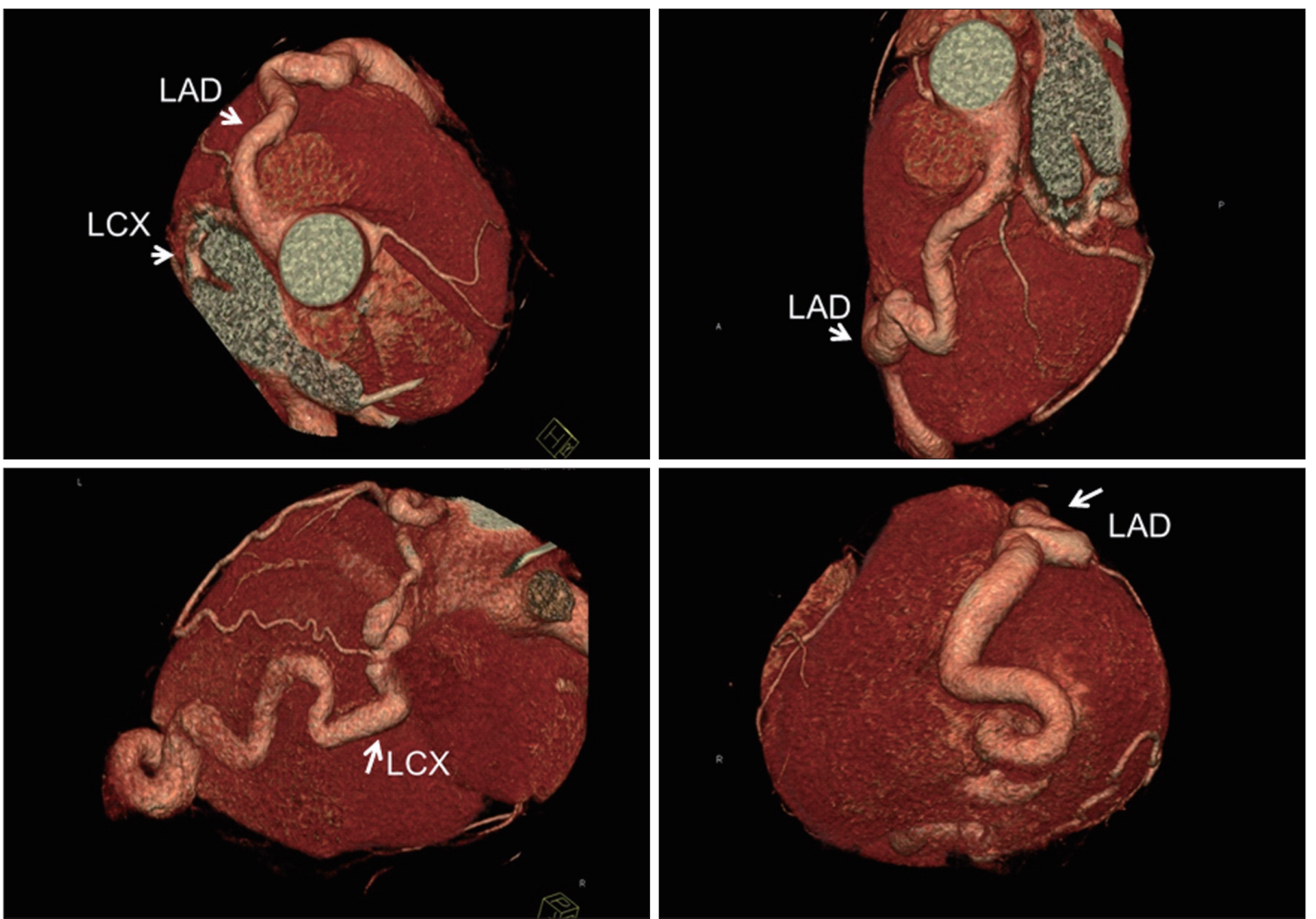

Fig. 2. Coronary computed tomography showed markedly dilated and serpentine whole left coronary arteries. LAD: left anterior descending artery, LCX: left circumflex artery. 

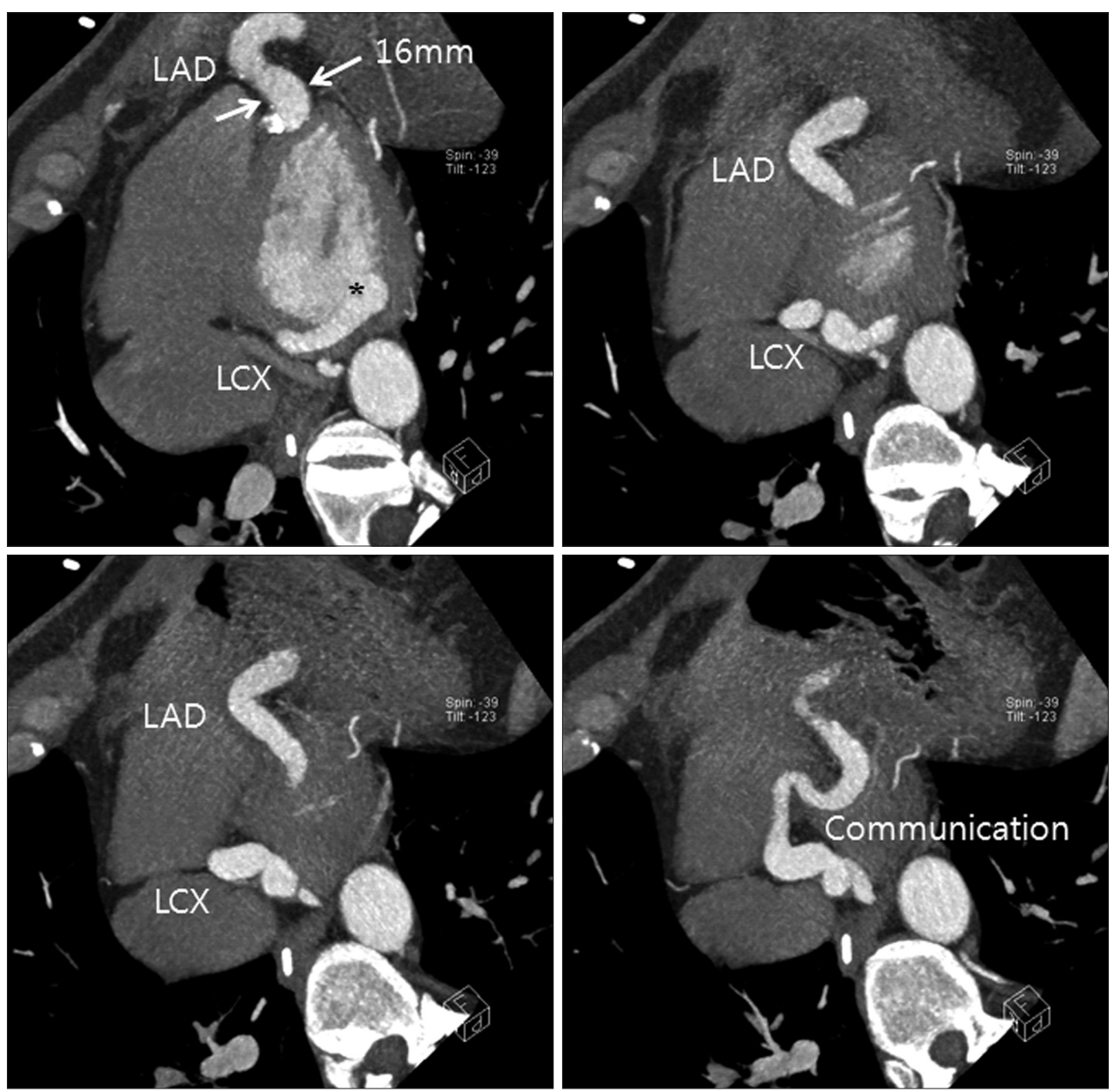

Fig. 3. Coronary computed tomography revealed dilated left coronary arteries and the drainage site to the left ventricle (asterisk). LAD: left anterior descending artery, LCX: left circumflex artery.

of CAF. No clinical events occurred during his admission. The patient visited outpatient clinic a month after discharge without clinical events or symptoms.

\section{DISCUSSION}

CAF communicating with the cardiac chambers are called coronary cameral fistula, as in our case. There have been many cases of coronary artery fistula. However, the incidence of coronary cameral fistula is very low and coronary cameral fistula involving left ventricle has been very rarely reported. ${ }^{45)}$ This case is also unique because almost whole left coronary artery was dilated and looked like cystic lesion in the apical portion, which could be clearly detected by transthoracic Doppler echocardiography. The majority of coronary cameral fistula (up to 90\%) drains into the right-sided chambers of the heart, while only $10 \%$ of coronary cameral fistula shows communications with the left-sided chambers or both left and right-sided chambers. ${ }^{6}$ Doppler echocardiography is a good screening imaging tool for the diagnosis of CAF, but evaluation of whole anatomy of CAF can be best visualized by coronary CT image.

Clinical presentations generally depend on the hemody- namic or anatomic significance of the lesion. The natural history of CAF is variable. Patients can be asymptomatic during their entire life. Chest pain, exertional dyspnea and fatigue may develop, but many patients do not suffer from any symptoms. ${ }^{7)}$ The mechanism of symptoms appeared to be coronary steal phenomenon and diastolic overload. ${ }^{8}$ The most common complication is myocardial ischemia due to coronary steal phenomenon which occurs in $15 \%$ of patients with CAF." Congestive heart failure and arrhythmia could be caused by excessive loading of cardiac chambers. Intravascular thrombosis, infective endocarditis, and rarely hemopericardium due to rupture of aneurysmal coronary artery might be complications.

The best therapy for CAF remains controversial. Surgical closure of CAF may have benefit for the patients with large, hemodynamically significant $\mathrm{CAF}^{10)}$ There were several reasons for not doing any surgical interventions for this patient. First, this pathology was incidentally found without any cardiovascular symptom, and may carry only mild risk in undergoing laparoscopic surgery. Therefore, the first thing we had to do for this patient was to let the surgeon not to postpone this necessary surgery because of the cardiac problem. Second, 
good functional status of this patient indicates low possibility of coronary steal causing myocardial ischemia due to this pathology. Lastly, surgical treatment for this coronary cameral fistula was not technically easy, because almost entire portion of the coronary artery was dilated as noticed in coronary CT.

\section{SUPPLEMENTARY MOVIE LEGENDS}

Movie 1. The parasternal long axis view revealed abnormal color flow within left ventricle predominantly during diastole.

Movie 2. The parasternal short axis view revealed diastoledominant abnormal color flow draining from posterior left ventricular wall.

Movie 3. Dilated large vascular structure was detected in the apical area.

Movie 4. Abnormal vascular structure was originated from basal posterior wall and drained into the left ventricular cavity.

\section{REFERENCES}

1. Ata Y, Turk T, Bicer M, Yalcin M, Ata F, Yavuz S. Coronary arteriovenous fistulas in the adults: natural history and management strategies. $J$ Cardiothorac Surg 2009;4:62.

2. Fernandes ED, Kadivar H, Hallman GL, Reul GJ, Ott DA, Cooley DA. Congenital malformations of the coronary arteries: the Texas Heart In- stitute experience. Ann Thorac Surg 1992;54:732-40.

3. Sommer RJ, Hijazi ZM, Rhodes JF Jr. Pathophysiology of congenital heart disease in the adult: part I: Shunt lesions. Circulation 2008;117: 1090-9.

4. Mangukia CV. Coronary artery fistula. Ann Thorac Surg 2012;93: 2084-92.

5. Mohanty SK, Ramanathan KR, Banakal S, Muralidhar K, Kumar P. An interesting case of coronary cameral fistula. Ann Card Anaesth 2005;8:152-4.

6. Roberts WC. Major anomalies of coronary arterial origin seen in adulthood. Am Heart J 1986;111:941-63.

7. Vavuranakis M, Bush CA, Boudoulas H. Coronary artery fistulas in adults: incidence, angiographic characteristics, natural history. Cathet Cardiovasc Diagn 1995;35:116-20.

8. Stierle U, Giannitsis E, Sheikhzadeh A, Potratz J. Myocardial ischemia in generalized coronary artery-left ventricular microfistulae. Int $J$ Cardiol 1998;63:47-52.

9. Valente AM, Lock JE, Gauvreau K, Rodriguez-Huertas E, Joyce C, Armsby L, Bacha EA, Landzberg MJ. Predictors of long-term adverse outcomes in patients with congenital coronary artery fistulae. Circ Cardiovasc Interv 2010;3:134-9.

10. Schumacher G, Roithmaier A, Lorenz HP, Meisner H, Sauer U, Müller KD, Sebening F, Bühlmeyer K. Congenital coronary artery fistula in infancy and childhood: diagnostic and therapeutic aspects. Thorac Cardiovasc Surg 1997;45:287-94. 